\title{
Fusion Laser Engineering
}

\author{
John R. Murray \\ Lawrence Livermore National \\ Laboratory \\ National Ignition Facility Project \\ PO Box 808 L-462 \\ Livermore, California 94550 \\ E-mail: jrmurray65@alum.mit.edu \\ John M. Soures \\ University of Rochester \\ Laboratory for Laser Energetics \\ National Laser Users' Facility \\ 250 East River Road \\ Rochester, New York 14623 \\ E-mail: jsou@lle.rochester.edu
}

The National Ignition Facility (NIF) now under construction at Lawrence Livermore National Laboratory contains a large frequency-tripled neodymium glass laser system designed to deliver approximately $2 \mathrm{MJ}$ of ultraviolet laser light in nanosecond pulses to targets for the study of high-energy-density physics and inertial confinement fusion. When all 192 laser beams are operational in 2008 it will dwarf any currently operating laser system, and even with only four beams now operating it is among the largest and most energetic of such systems. This special section is a collection of papers covering important issues in the optical engineering of large lasers such as NIF. A number of other papers on NIF engineering issues can be found in the Proceedings of SPIE, Volume 5341.

The first paper in this special section by Miller, Moses, and Wuest is an overview of the NIF project and the applications for which the facility was designed. The following papers discuss specific issues in greater depth. Spaeth et al. discuss the NIF laser architecture, the effect of optical performance specifications on the focal spot size, and some aspects of cleanliness in large laser systems. Bonanno discusses the strategy for assembling NIF from "line-replaceable units" that are assembled in a cleanroom and transported to the laser system in sealed containers that mate with the laser enclosures and allow clean installations without maintaining cleanroom standards throughout the facility. Zacharias et al. discuss the alignment and wavefront control systems that allow beams to strike the target within $\pm 50 \mu \mathrm{m}$ after a beam path of about $350 \mathrm{~m}$. Shaw et al. discuss a laser performance operations model that is used to set up the laser for a shot, and compare the predictions of the model to data from the first four operating beams. Ermolaeva et al. discuss the design and performance of a custom optical fiber that was developed for use in NIF ultraviolet diagnostics. Finally, Honig discusses what has been learned about cleanliness issues in large lasers from past operating systems, and how their cleanliness compares to NIF using the new assembly strategies and techniques.

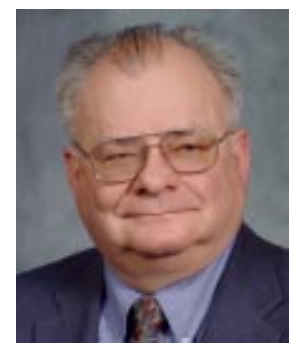

John R. Murray received his SB and $\mathrm{PhD}$ degrees in physics from the Massachusetts Institute of Technology in 1965 and 1970. Since 1972, he has worked in the Laser Program at Lawrence Livermore National Laboratory (LLNL), mostly on the technology of large laser systems for inertial confinement fusion including excimer and other gas lasers, neodymium glass lasers, and stimulated scattering processes in large lasers. In the early nineties, he was project scientist for the Beamlet Demonstration Project that studied the technology proposed for NIF. From 1995 to 2001 he was editor-in-chief of Applied Optics, and from 2000 to 2002 he was chairman of the OSA Publications Council. He retired from LLNL in September 2003, but still participates parttime in NIF laser development. He is a Fellow of the Optical Society of America.

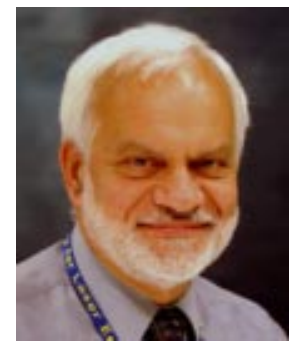

John M. Soures is manager of the $\mathrm{Na}$ tional Laser Users' Facility (NLUF) and coordinator for external users of the OMEGA Laser System at the Laboratory for Laser Energetics (LLE) at the University of Rochester. NLUF is a unique program, funded through the Office of Inertial Fusion of the Department of Energy (DOE), that allows non-LLE researchers to conduct experiments on OMEGA without a direct facility charge. Approved high-energy-density physics experiments are conducted by inves- 
tigators from U.S. universities, national laboratories, and industry in a variety of areas including inertial fusion, laboratory astrophysics, radiation hydrodynamics, hydrodynamic instabilities, studies of the equation of state of materials, plasma physics, x-ray laser physics, XUV spectroscopy, and high-temperature and highdensity plasma diagnostics development. In addition to serving as NLUF manager and coordinator for external users, Dr. Soures is a member of the LLE Advisory Committee (IFE subcommittee chairman) and the editor of the LLE DOE monthly report. Since joining LLE in 1970 and becoming a senior scientist in 1972, Dr. Soures has held a variety of leadership positions. Most notably, he has served as group leader for the Glass Laser Development and Laser Fusion Experiments Groups, deputy director for LLE, director of the Experimental Division, and deputy project manager for the National Ignition Facility/LLE. Dr. Soures has served as a consultant to the Naval Research Laboratory, Lawrence Livermore Na- tional Laboratory, Eastman Kodak Co., Link Foundation, the General Electric Co., and Oak Ridge National Laboratory. He is a fellow of the American Physical Society and was awarded the 1993 American Physical Society Award for Excellence in Plasma Physics Research. He has served as a reviewer for many journals as well as the National Science Foundation and the Department of Energy. Dr. Soures has served as co-chairman of the Conference on High-temperature Plasma Diagnostics, and as an organizing committee member for several meetings of the Division of Plasma Physics of the American Physical Society and of the Conference on Lasers and Electro-Optics. Dr. Soures received a BS in physics (1965), an MS in mechanical engineering and aerospace sciences (1967), and a PhD in mechanical and aerospace sciences (1970), all from the University of Rochester. Dr. Soures has authored, coauthored, or presented more than 250 publications and technical papers. $\mathrm{He}$ is the co-inventor of three laser technology patents. 